Wright State University

CORE Scholar

$1-27-1997$

\title{
Optical Properties of GaN Grown on ZnO by Reactive Molecular Beam Epitaxy
}

\author{
F. Hamdani
}
A. Botchkarev
W. Kim
H. Morkoç
M. Yeadon

See next page for additional authors

Follow this and additional works at: https://corescholar.libraries.wright.edu/physics

Part of the Physics Commons

\section{Repository Citation}

Hamdani, F., Botchkarev, A., Kim, W., Morkoç, H., Yeadon, M., Gibson, J. M., Tsen, S. Y., Smith, D. J., Reynolds, D. C., Look, D. C., Evans, K. R., Litton, C. W., Mitchel, W. C., \& Hemenger, P. (1997). Optical Properties of GaN Grown on ZnO by Reactive Molecular Beam Epitaxy. Applied Physics Letters, 70 (4), 467-469.

https://corescholar.libraries.wright.edu/physics/689

This Article is brought to you for free and open access by the Physics at CORE Scholar. It has been accepted for inclusion in Physics Faculty Publications by an authorized administrator of CORE Scholar. For more information, please contact library-corescholar@wright.edu. 


\section{Authors}

F. Hamdani, A. Botchkarev, W. Kim, H. Morkoç, M. Yeadon, J. M. Gibson, S.-C. Y. Tsen, David J. Smith, Donald C. Reynolds, David C. Look, K. R. Evans, Cole W. Litton, William C. Mitchel, and P. Hemenger 


\section{AIP Appiled Physics \\ Letters}

\section{Optical properties of GaN grown on ZnO by reactive molecular beam epitaxy}

F. Hamdani, A. Botchkarev, W. Kim, H. Morkoç, M. Yeadon et al.

Citation: Appl. Phys. Lett. 70, 467 (1997); doi: 10.1063/1.118183

View online: http://dx.doi.org/10.1063/1.118183

View Table of Contents: http://apl.aip.org/resource/1/APPLAB/v70/i4

Published by the American Institute of Physics.

\section{Related Articles}

Photoluminescence of antimony sprayed indium arsenide quantum dots for novel photovoltaic devices J. Appl. Phys. 113, 093102 (2013)

Surface potential effect on excitons in AIGaN/GaN quantum well structures

Appl. Phys. Lett. 102, 082110 (2013)

Visible single-photon emission from a nitrogen impurity center in AIAs

Appl. Phys. Lett. 102, 062107 (2013)

Photoluminescence of radial heterostructured GaAs/AIGaAs/GaAs nanowires

J. Appl. Phys. 113, 064315 (2013)

Strong enhancement of Eu+3 luminescence in europium-implanted GaN by Si and Mg codoping Appl. Phys. Lett. 102, 061115 (2013)

\section{Additional information on Appl. Phys. Lett.}

Journal Homepage: http://apl.aip.org/

Journal Information: http://apl.aip.org/about/about_the_journal

Top downloads: http://apl.aip.org/features/most_downloaded

Information for Authors: http://apl.aip.org/authors

\section{ADVERTISEMENT}

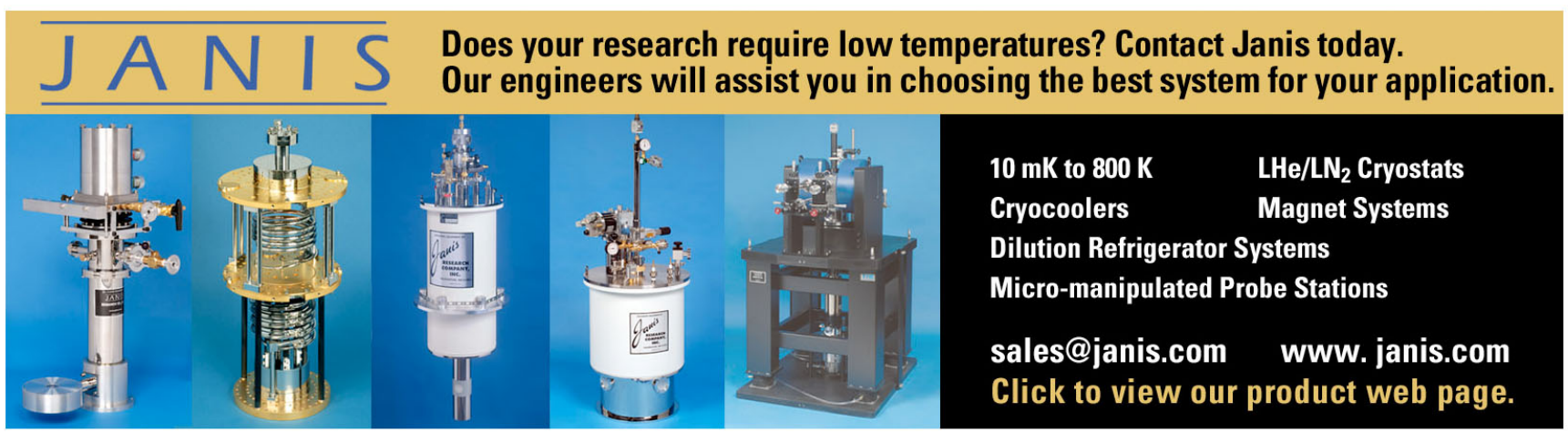




\title{
Optical properties of GaN grown on $\mathrm{ZnO}$ by reactive molecular beam epitaxy
}

F. Hamdani, ${ }^{\text {a) }}$ A. Botchkarev, W. Kim, and H. Morkoç ${ }^{\text {b) }}$

Materials Research Laboratory and Coordinated Science Laboratory, University of Illinois at Urbana-

Champaign, Urbana, Illinois 61801

M. Yeadon and J. M. Gibson

Materials Research Laboratory, University of Illinois at Urbana-Champaign, Urbana, Illinois 61801

S.-C. Y. Tsen and David J. Smith

Department of Physics and Astronomy and Center for Solid State Science, Arizona State University, Tempe, Arizona 85287

D. C. Reynolds and D. C. Look

University Research Center, Wright State University, Dayton, Ohio 45435

K. Evans and C. W. Litton

Wright Laboratory, WL/AADP, Wright Patterson AFB, Ohio 45433-7323

W. C. Mitchel and P. Hemenger

Wright Laboratory, WL/MLPO, Wright Patterson AFB, Ohio 45433

(Received 7 October 1996; accepted for publication 20 November 1996)

\begin{abstract}
High quality wurtzite GaN epilayers have been grown on $\mathrm{ZnO}(0001)$ substrates by reactive molecular beam epitaxy. Photoluminescence and reflectivity measurements point to high quality presumably due to the near match of both the crystal lattice parameter and the stacking order between $\mathrm{GaN}$ and $\mathrm{ZnO}$. In addition, the good films lack the characteristic yellow photoluminescence band. Any misorientation of the $\mathrm{GaN}$ epilayer planes with respect to the $\mathrm{ZnO}$ substrate is not detectable with polarized reflectivity. The $\mathrm{x}$-ray double crystal diffraction measurements indicate this misorientation is much smaller than those for $\mathrm{GaN}$ epilayers on $\mathrm{SiC}$ and $\mathrm{Al}_{2} \mathrm{O}_{3}$. (C) 1997 American Institute of Physics. [S0003-6951(97)01304-1]
\end{abstract}

$\mathrm{GaN}$ is a wide gap semiconductor with great promise for optoelectronic and high-temperature/high-power device applications. ${ }^{1-4}$ The challenge of growing high quality and defect-free $\mathrm{GaN}$ and its alloys, $\mathrm{In}_{1-x} \mathrm{Ga}_{x} \mathrm{~N}$ and $\mathrm{Al}_{1-x} \mathrm{Ga}_{x} \mathrm{~N}$, is still formidable due to the lack of lattice matched substrates. Most of the previous work has been devoted to the growth of $\mathrm{GaN}$ on $\mathrm{Al}_{2} \mathrm{O}_{3}$ by metal organometallic vapor pressure epitaxy (MOVPE) $)^{2,3}$ or molecular beam epitaxy (MBE). ${ }^{5}$ Despite the demonstration of light emitting diode ${ }^{2}$ and pulsed laser devices ${ }^{3}$ grown on $\mathrm{Al}_{2} \mathrm{O}_{3}$, the density of defects is probably still too high $^{2}$ to achieve the desired violet and/blue lasers that operate continuously at room temperature with the required longevity, as well as high-power electronic devices. ${ }^{4}$

Successful MBE and MOVPE growth of wurtzitic GaN has been demonstrated on various substrates such as $6 \mathrm{H}-\mathrm{SiC},{ }^{6} \mathrm{MgAl}_{2} \mathrm{O}_{4},{ }^{7} \mathrm{Si}(111),{ }^{8} \mathrm{GaAs},{ }^{9}$ and $\mathrm{ZnO}(0001) .{ }^{10,11}$ Sverdlov et al. ${ }^{6}$ discussed the possible causes of the dense network of threading defects in epitaxial hexagonal $\mathrm{GaN}$ films grown on nonisomorphic substrates and have suggested that the stacking mismatch between the substrate and the epitaxial layer is responsible for many of these defects. Transmission electron microscopy (TEM) experiments ${ }^{6,11}$ have revealed the presence of planar defects in $\mathrm{GaN}$ epitaxial layers grown on $\mathrm{Al}_{2} \mathrm{O}_{3}$ and $\mathrm{SiC}$. Two types of defects have been considered: double positioning boundaries, also called stacking mismatch boundaries (SMB), and inversion domain

a)Electronic mail: hamdani@ux1.cso.uiuc.edu

${ }^{b)}$ On sabbatical leave at Wright Laboratories. boundaries (IDB). In the cases of SMB there is an equal probability of nucleating two different face-centered-cubic (fcc) stacking sequences $(A B C$ and $A C B)$. For example, the stacking sequence in $6 \mathrm{H}-\mathrm{SiC}$ is $A B C A C B$, so that three stacking sequences would be possible for wurtzite GaN: substrate $A B C$ leading to $B C B C \mathrm{GaN}$; substrate $B C A$ leading to $C A C A \mathrm{GaN}$; and substrate $C B A$ leading to $B A B A \mathrm{GaN}$.

$\mathrm{ZnO}$ is being considered as a suitable substrate for $\mathrm{GaN}$ growth because of its stacking order match and close lattice match. The lattice mismatch between $\mathrm{GaN}$ and $\mathrm{ZnO}$ is $\varepsilon$ $=0.017$, which leads to a range of critical thickness between 80 and $120 \AA$, estimated using different elastic models. ${ }^{12}$ This implies that coherently strained layers of $\mathrm{GaN}$ could be pseudomorphically grown with thickness up to about $100 \AA$ on $\mathrm{ZnO}$ substrates. Since the steps on (0001) $2 \mathrm{H} \mathrm{ZnO}$ would be bilayer ones, SMB-type defects would not be expected to occur. Matsuoka et al. ${ }^{10}$ have used $\mathrm{Zn}$-face $\mathrm{ZnO}$ substrates to grow the lattice matched alloy $\operatorname{In}_{0.22} \mathrm{Ga}_{0.78} \mathrm{~N}$. More recently, $\mathrm{ZnO}$ has been used as a compliant buffer layer ${ }^{13,14}$ in the growth of high quality GaN. Nevertheless, the $\mathrm{ZnO}$ buffer layers grown on substrates with which they do not share a common stacking order suffer from stacking faults that would cause the GaN films grown on them to still have high density of SMBs. It should, therefore, not come as a surprise that the quality of epitaxial GaN grown on compliant buffer layers is still inferior to the quality of the buffer layer used. ${ }^{14}$ In this letter, we present results of $\mathrm{GaN}$ grown, by reactive $\mathrm{MBE},{ }^{5}$ on high quality bulk $\mathrm{ZnO}(0001)$ substrates.

Figure 1 shows the $4.2 \mathrm{~K}$ photoluminescence (PL) and the reflectivity data obtained on a $\mathrm{ZnO}(0001)$ substrate. The 


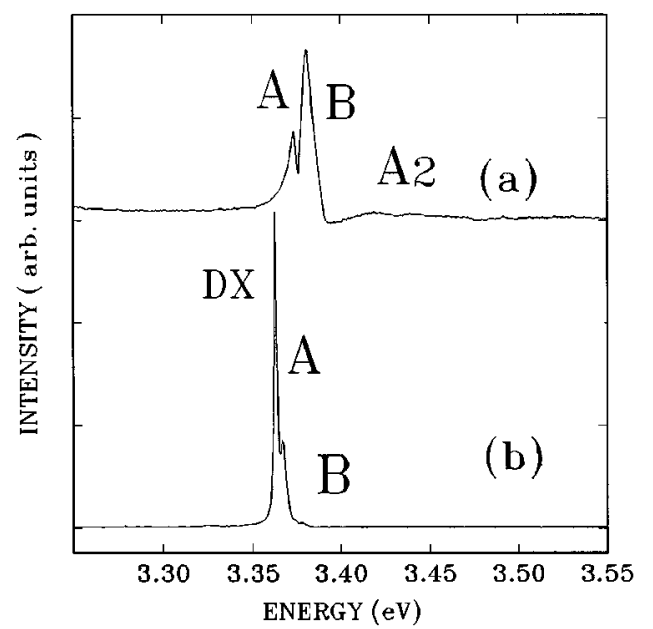

FIG. 1. (a) Reflectivity and (b) photoluminescence spectra of $\mathrm{ZnO}(0001)$ substrate at $4.2 \mathrm{~K}$ and with light configuration $k \| c$ and $E$ perpendicular to $c$. Labels $A, B, A_{2}$, and $D^{\circ} X$ are given as identifications of free and bound excitons, respectively.

positions of the free and bound excitons are given as follows: $A$-exciton (3375 meV), $B$-exciton $(3386 \mathrm{meV})$, and $D^{\circ} X$ (3364 meV). The PL peaks have a full width at halfmaximum (FWHM) of $3 \mathrm{meV}$, which indicate a reasonably high quality $\mathrm{ZnO}$ substrate. The observation of the $A$ and $B$ free excitons using different polarized light confirms the orientation of the substrate. However, the substrates suffer from rather poor surface preparation, limiting the quality of the GaN films. We note that the first excited $A_{2}$ exciton is also observed in the reflectivity spectrum of the $\mathrm{ZnO}$ substrate itself, and that the energy position of $A_{2}$ exciton is consistent with the high exciton binding energy of $67 \mathrm{meV}$ in $\mathrm{ZnO}$. The observation of the excited free exciton indicates that the substrate has low carrier concentration and very good crystalline quality.

Figure 2 shows PL and reflectivity spectra of GaN epilayers grown by reactive ammonia $\mathrm{MBE}$ on $\mathrm{ZnO}$, at $780{ }^{\circ} \mathrm{C}$. The reflectivity spectrum shows pronounced features at

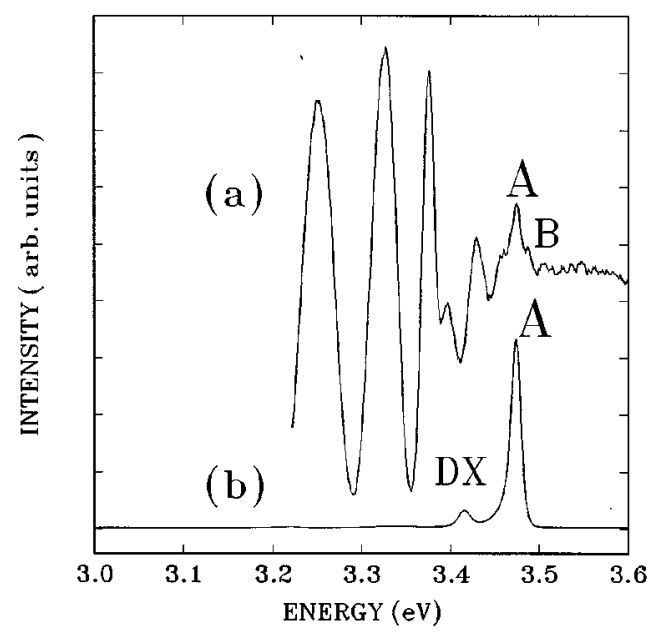

FIG. 2. (a) Reflectivity and (b) photoluminescence spectra of GaN/ $\mathrm{ZnO}(0001)$ at $4.2 \mathrm{~K}$ and with light configuration $k \|_{c}$ and $E$ perpendicular to $c$. Labels $A, B$, and $D^{\circ} X$ are given as identifications of free and bound excitons, respectively.

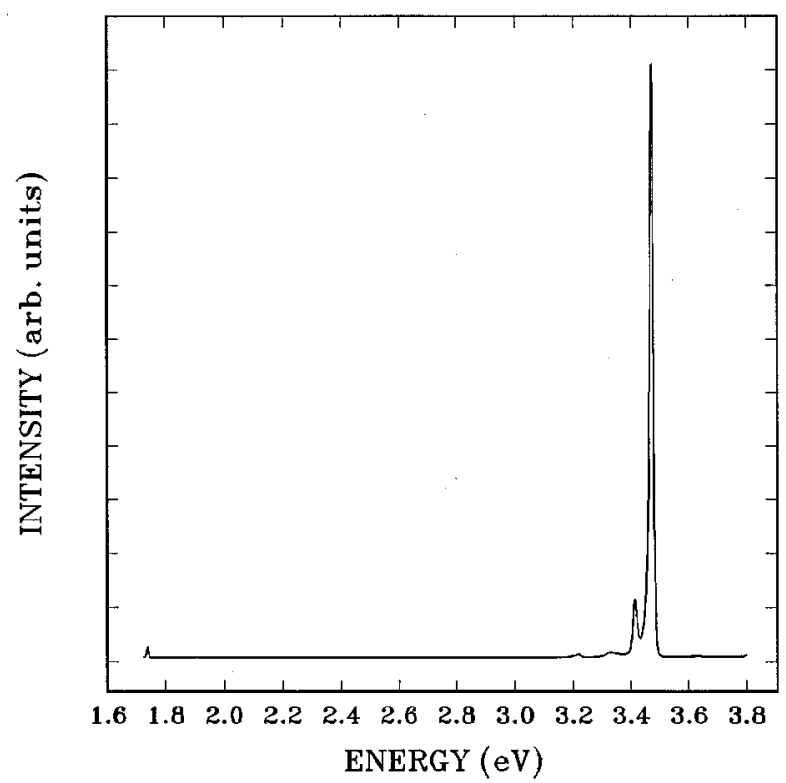

FIG. 3. Photoluminescence spectrum of $\mathrm{GaN} / \mathrm{ZnO}$ at $4.2 \mathrm{~K}$. The yellow band is not observed at either room temperature or $4.2 \mathrm{~K}$, even with a high detection sensitivity (wide open monochromator slits, $600 \mu \mathrm{m}$ ).

higher energy corresponding to the $A(3480 \mathrm{meV})$ and $B$ $(3493 \mathrm{meV})$ free excitons. The oscillations observed in the reflectivity spectrum at lower energies are due to interference fringes between the reflections from the surface of $\mathrm{GaN}$ and the $\mathrm{GaN} / \mathrm{ZnO}$ interface. The fringe period gives an estimate of the GaN thickness at about $1.5 \mu \mathrm{m}$, which is consistent with the growth rate of $0.8 \mu \mathrm{m} / \mathrm{h}$. It is worth noting that the discontinuity in the oscillation fringes occurring in the range between 3.38 and $3.45 \mathrm{eV}$ is due to the spectral dispersion of the refractive index of $\mathrm{ZnO}$ close to the energy gap. The PL spectra show a peak at the same energy position as the $A$ exciton in the reflectivity spectra, which allowed us to attribute this peak to the free $A$ exciton. Despite the rather poor substrate surface preparation, the PL and reflectance widths of the excitonic transitions (FWHM $\sim 8 \mathrm{meV}$ ) are approximately in the same range of the best results obtained on sapphire substrates by MBE. It is very important to note the lack of any yellow band luminescence in the room and lowtemperature PL spectra of the samples grown on $\mathrm{ZnO}$ (0001) substrates. As shown in Fig. 3, the near band-edge transitions, i.e., free and shallow bound excitons, are the only transitions observed in these samples. Even at a high detection sensitivity (wide open monochromator slit width of $600 \mu \mathrm{m}$ ), the yellow band was completely absent.

Recent first-principles calculations of domain wall energies for both IDB and SMB in GaN (Ref. 15) indicate that the IDB does not induce electronic states in the band gap, but that SMBs give rise to occupied $\mathrm{N}$-derived interface states in the band gap. Therefore, one source of the commonly observed yellow band, may be the SMBs. ${ }^{15}$ Other likely sources may have to do with electron-hole recombination processes involving impurities or native point defects such as deep acceptor levels (Ref. 16) and Ga vacancies. ${ }^{17}$ Consequently, an argument can be made that the absence of any yellow PL signal in our $\mathrm{GaN}$ samples grown on $\mathrm{ZnO}$, as shown in Fig. 3, is an indication of a reduced density of 
defects. TEM results on our $\mathrm{GaN}$ grown on $\mathrm{ZnO}$ indicate much improved quality near the surface over those on sapphire, and defects at the epilayer-substrate interface caused by poor $\mathrm{ZnO}$ surface preparation. Atomic force microscopy results indicate that $\mathrm{GaN}$ grown on $\mathrm{ZnO}$ presents a surface roughness comparable to $\mathrm{GaN}$ grown on $\mathrm{Al}_{2} \mathrm{O}_{3}$.

The strain induced both by lattice mismatch and the difference between the expansion coefficients of the layers and the substrate induces a shift and an alteration of the excitonic transitions in GaN. Gil et al. ${ }^{18}$ have presented a theoretical model using the Pikus and Bir Hamiltonian, taking into account the relaxation of the thermal and lattice mismatch between GaN and the substrate, in order to fit the energy shift of both the conduction and valence bands. It is noted that GaN layers grown on sapphire undergo compressive strain, while $\mathrm{GaN}$ layers grown on $\mathrm{SiC}$ are under tensile strain. An accurate estimate of the thermal strain $\left(\varepsilon_{\text {th }}\right)$ due to the difference between the thermal expansion coefficients of $\mathrm{GaN}$ and the particular substrate is given by

$$
\varepsilon_{\mathrm{th}}=\left[\Delta a_{l}(T)-\Delta a_{s}(T)\right] / \Delta a_{s}(T),
$$

where $\Delta a_{l}(T)$ and $\Delta a_{s}(T)$ represent the variation of the lattice parameter between the growth temperature and room temperature for the GaN layer and the substrate, respectively. Our estimate of $\varepsilon_{\mathrm{th}}$, using the temperature dependence of the thermal expansion coefficient ${ }^{19}$ gives a positive value for $\varepsilon_{\text {th }}$ for both sapphire and $\mathrm{ZnO}$ substrates and a negative value for $\mathrm{SiC}$ substrates. This is consistent with the energy position of the free exciton observed in both reflectivity and photoluminescence spectra. ${ }^{18}$ Note that the compressive thermal strain induced by a $\mathrm{ZnO}$ substrate is smaller than that induced by sapphire substrates. This implies that the cracking of GaN layers observed in growth on $\mathrm{Al}_{2} \mathrm{O}_{3}$ and $\mathrm{SiC}$ substrates could be avoided where $\mathrm{ZnO}$ is used as a substrate. In accordance with the optical data, $\mathrm{x}$-ray double crystal diffraction results obtained in samples grown both on $\mathrm{ZnO}$ and sapphire indicate that the value of the lattice parameter perpendicular to the interface of $\mathrm{GaN}$ grown on $\mathrm{ZnO}$ is closer to that of bulk GaN.

The intensity of reflectance peaks corresponding to the free exciton transitions is a function of their oscillator strengths. ${ }^{20}$ Using linearly polarized reflectance measurements on $\mathrm{GaN}$ grown on sapphire, we have observed a variation of the exciton oscillator strength, which indicates that such $\mathrm{GaN}$ layers are tilted with respect to the substrate axis. Our results for $\mathrm{GaN}$ samples grown on $\mathrm{ZnO}$ indicate an absence of any tilting effect. Double crystal x-ray diffraction measurements performed by rotating the samples $180^{\circ}$ show a smaller variation in the peak position for growth on $\mathrm{ZnO}$ than for growth on $\mathrm{SiC}$ or $\mathrm{Al}_{2} \mathrm{O}_{3}$.
In conclusion, photoluminescence and reflectance data show that high quality GaN epilayers can be grown on $\mathrm{ZnO}(0001)$ substrates using reactive ammonia MBE. The absence of the yellow photoluminescence band indicates a reduced defect density in $\mathrm{GaN}$ grown on $\mathrm{ZnO}$ substrates. X-ray measurements as well as polarized optical data confirm that the GaN epilayers are well oriented with respect to the substrate axis. The lower strain offered by $\mathrm{ZnO}$ substrates may eliminate cracks occurring for growth on sapphire and $\mathrm{SiC}$ substrates. Further investigations on the effect of surface polarity and different buffer layers are under way.

The work at the University of Illinois was funded by grants from the Office of Naval Research, with Dr. C. E. Wood, Dr. Y. S. Park, and M. Yoder monitoring, and the Air Force of Science Research with Dr. G. L. Witt monitoring.

${ }^{1}$ H. Morkoç, S. Strite, G. B. Gao, M. E. Lin, B. Sverdlov, and M. Burns, J. Appl. Phys. 76, 1363 (1994).

${ }^{2}$ S. D. Lester, F. A. Ponce, M. G. Craford, and D. A. Steigerwald, Appl. Phys. Lett. 66, 1249 (1995); S. Nakamura, M. Senoh, N. Iwasa, and S. I. Nagahama, ibid. 67, 1868 (1995).

${ }^{3}$ S. Nakamura, M. Senoh, S. I. Nagahama, N. Iwasa, T. Yamada, T. Matsushita, H. Kiyoku, and Y. Sugimoto, Appl. Phys. Lett. 68, 2105 (1996).

${ }^{4}$ Ö Aktas, W. Kim, Z. Fan, A. Bothkarev, A. Salvador, S. N. Mohammad, B. Sverdlov, and H. Morkoç, Electron. Lett. 31, 1389 (1995).

${ }^{5}$ W. Kim, Ö Aktas, A. Botchkarev, A. Salvador, S. N. Mohammad, and H. Morkoç, J. Appl. Phys. 79, 7657 (1996).

${ }^{6}$ B. N. Sverdlov, G. A. Martin, H. Morkoç, and D. J. Smith, Appl. Phys. Lett. 67, 2063 (1995).

${ }^{7}$ A. Kuramata, K. Hirino, K. Domen, K. Shinohara, and T. Tanahashi, Appl. Phys. Lett. 67, 2521 (1995).

${ }^{8}$ A. Watanabe, T. Takeuchi, K. Hirosawa, H. Amano, K. Hiramatsu, and I. Akasaki, J. Cryst. Growth 128, 391 (1993).

${ }^{9}$ S. Fujieda and Y. Matsumoto, Jpn. J. Appl. Phys. 30, L 1665 (1991).

${ }^{10}$ T. Matsuoka, N. Yoshimoto, T. Sasaki, and A. Katsui, J. Electron. Mater. 21, 157 (1992).

${ }^{11}$ Z. Sitar, M. J. Paisley, B. Yan, and R. F. Davis, Mater. Res. Soc. Symp. Proc. 162, 537 (1990); P. J. Born and D. S. Robertson, J. Mater. Sci. 15, 3003 (1980).

${ }^{12}$ J. Singh, Physics of Semiconductors and Their Heterostructures (McGraw-Hill, New York, 1993), Chap. 18, p. 714.

${ }^{13}$ T. Detchprohm, H. Amano, K. Hiramatsu, and I. Akasaki, J. Cryst. Growth 128, 384 (1993).

${ }^{14}$ M. A. L. Johnson, S. Fujita, W. H. Rowland, W. C. Hughes, J. W. Cook, and J. F. Schetzina, J. Electron. Mater. 25, 855 (1996).

${ }^{15}$ J. E. Northrup, J. Neugebauer, and L. T. Romano, Phys. Rev. Lett. 77, 103 (1996).

${ }^{16}$ P. Perlin, T. Suski, H. Teisseyre, M. Leszczynski, I. Grzegory, J. Jun, S. Porowski, P. Boguslawski, J. Bernholc, J. C. Chevrin, A. Polain, and T. D. Moustakas, Phys. Rev. Lett. 75, 296 (1995).

${ }^{17}$ J. Neugebauer and C. G. Van de Walle, Appl. Phys. Lett. 69, 503 (1996).

${ }^{18}$ B. Gil, O. Briot, and R. L. Aulombard, Phys. Rev. B 52, R17 028 (1995); B. Gil, F. Hamdani, and H. Morkoç, ibid. 54, 7678 (1996).

${ }^{19}$ Landolt-Börnstein (Springer-Verlag, Berlin, 1982), Vol. 17.

${ }^{20}$ M. Stoehr, F. Hamdani, J. P. Lascaray, and M. Maurin, Phys. Rev. B 44, 8912 (1991). 